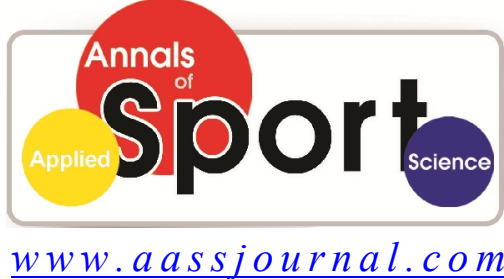

ISSN (Online): $2322-4479$

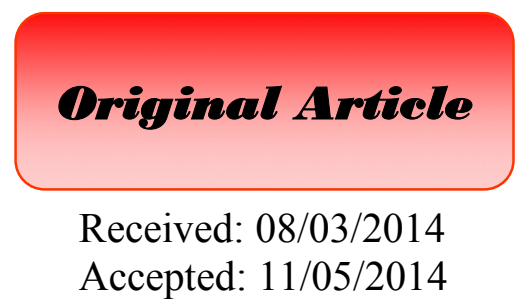

Accepted: 11/05/2014

\title{
Kinematics of Straight Right Punch in Boxing
}

\section{${ }^{1,2}$ Mahdi Cheraghi ${ }^{*}{ }^{2}$ Hamid Agha Alinejad, ${ }^{3}$ Ahmad Reza Arshi, ${ }^{4}$ Elham Shirzad}

1. National Olympic \& Paralympic Academy of I.R.Iran, Tehran, Iran.

2. Department of Physical Education and Sports Sciences, Tarbiat Modares University, Tehran, Iran.

3. Sports Engineering Division, Department of Biomedical Engineering, Amirkabir University of Technology (Tehran Polytechnic), Tehran, Iran.

4. Department of Sport Medicine, Faculty of Physical Education and Sports Sciences, University of Tehran, Tehran, Iran.

\section{ABSTRACT}

The purpose of this study was to describe biomechanical parameters of head, upper and lower body extremities during a straight right punch throw related to performance and injury mechanism. Subjects were eight elite right-handed male (age $20.4 \pm 2.1 \mathrm{yrs}$; height $177.4 \pm 8.5 \mathrm{~cm}$; mass $70.4 \pm 16.8 \mathrm{~kg}$ ) amateur boxers. 3D motion analysis was used to assess the kinematics of the right side extremities and head. Ensemble averaging of time normalized kinematic parameters was used to have better visual inspection. Results showed a similar pattern between subjects with some considerable variation in some parameters that pointed out to individualized pattern in elite boxers. Investigation of lower body joints kinematics explained boxers throw punch using leg drive. Stretch-shortening cycle detected in the technique implies potential for performance enhancing using plyometrics. Head velocity measured in anterior-posterior and medial-lateral direction would intensify potential head injuries.

Key Words: Boxing, Kinematics, Straight Right Punch, Ensemble Averaging, Stretch-Shortening Cycle, Head Injuries.

Corresponding Author:

Mahdi Cheraghi

E-mail: mahdicheraghi3@yahoo.com 


\section{INTRODUCTION}

Straight right punch, thrown by the rear hand in boxing, also known as reverse punch in karate, is a fundamental, scoremaking and powerful skill. Thrown often by dominant hand, the technique is very precise and could potentially alter competition result. The magnitude of force exerted at the point of impact is governed by a number of factors, amongst which are the force generated by the legs (1), degree of body rotation, and the distance over which the punch is thrown (2).

The introduction of computer scoring has resulted in greater emphasis on punching force and methods of force measurement (3). It has been shown that legs have a strong effect on impact force (4), through transferring momentum into the kinetic chain system based on conservation of angular momentum (5). However, the relationship between the magnitude of the impact force and the lower extremity kinematic parameters has not been fully investigated.

Atha et al. (1985) have studied some biomechanical characteristics of a straight punch, executed by a heavy weight professional boxer. These parameters were punch velocity at the point of contact, impact force and duration (6). Whiting, Gregor, and Finerman (1988) have measured 2D upper extremity kinematic features in four professional boxers and have found significant differences for shoulder and wrist velocity, elbow angle and angular velocity between straight right and left hook (7).

Although, there are a number of studies which examined head kinematics after impact and consecutive head injuries (812), there was found no study to investigate boxers' head kinematics during their own attack.
Thus, the objective of this study was to identify temporal and spatial parameters associated with a straight punch technique using upper and lower body kinematic data. The kinematic data could also be used to describe head kinematics while performing the technique.

\section{MATERIALS AND METHODS}

Participants. They were eight righthanded male (age $20.4 \pm 2.1 \mathrm{yrs}$; height $177.4 \pm 8.5 \mathrm{~cm}$; mass $70.4 \pm 16.8 \mathrm{~kg}$ ) Iranian international amateur boxers. All participants were in final conditioning days prior to an international tournament. Informed consent was obtained from all subjects. It was made clear to the participants that their status as volunteers meant that they were able to leave and withdraw from the study at any moment.

Protocol. Task constraint was to simulate a knock-out punch. After 15 min stretching and warm-up, all subjects were instructed to perform their maximum effort knock-out straight right (rear hand) punch to a foamed wood target $(30 \times 50 \times$ $5 \mathrm{~cm}$ ). The target was adjusted for individual boxers to their preferred height so that the task constraint could be met by delivering their best knock-out punch to a shadow opponent head. Introductory punches were used to satisfy the boxers and the supervising coach that no unwarranted risk of injury was involved. To simulate real condition, one Light Emitting Diode (LED) was attached to the top of the target-pad. Subjects were instructed to throw punch as fast as they could once the LED was lit up.

Reflective markers were placed over the bony landmarks as follows: Segments and joints' kinematics including the head (right side template), the shoulder (acromion process), the elbow (lateral epicondyle of humerus), the wrist (styloid 
process of the radius), the fist (fifth metacarpal distal head), the hip (anterior superior iliac spines (ASIS)), the knee (lateral femoral epicondyle), the ankle (lateral malleous) and the foot (between two and three metatarcal distal head) by a same level one anthropometrist were identified. The trials were recorded at a frequency of $250 \mathrm{~Hz}$ using two synchronized high-speed camera (KODAK (R) Motion Corder Analyzer, SR series) which were placed approximately at rightangles to one another. Three-dimensional marker coordinates were tracked using WINanalyze ${ }^{\circledR} \quad$ software version 1.4 (Mikromak® 1998). A calibration frame $(1040 \mathrm{~mm} \times 1040 \mathrm{~mm} \times 2040 \mathrm{~mm})$ with 28 control markers were also used to calibrate the $3 \mathrm{D}$ performance area. Three trials which were chosen by the boxer were selected for further processing and analysis (13).

Analysis. Data processing was conducted on kinematic parameters within the range of onset of motion and point of impact. Impact was defined as the moment of initial contact of glove with the target mat. The points were identified manually by visual inspection of the individual frames. All angles were defined as relative angles .The ensemble averaging (14) has been used to obtain a better sense of movement pattern of the techniques performed by boxers. Hence, ensemble averages of time normalized data for intended kinematic parameters were calculated to assist visual inspection. Time normalization of joint angles and head velocity was performed using quintic spline interpolation equations (15) using MINITAB ${ }^{\circledR} 13$ by $\mathrm{R}^{\wedge} 2>98 \%$ to provide a better illustration of the movement pattern in the form of a punch cycle.

Since the angular changes in ankle took place prior to other joints, punch cycle was defined as the onset of motion of the ankle up to the identified point of impact.

\section{RESULTS}

Results illustrated a similar trend in angle-time series of elbow, knee and ankle in all participants. For example, an initial partial elbow flex followed by an extension is observed in all participants (figure 1). This was a stretch shortening cycle (SSC) (16), involving the agonist muscle followed by a rapid shortening or concentric phase in an involuntary strategy to produce a more powerful punch. This issue was addressed by van Ingen Schenau, Bobbert, and de Haan (1997) and is known as the principle of pre-stretch $(17,18)$.

Some specific kinematic variables are illustrated by maxVtime which is the time of maximum velocity before impact; eccentric time or the onset of eccentric phase before impact; concentric time or onset of concentric phase before impact; $x$, $\mathrm{y}$ and $\mathrm{z}$ displacements which are displacement of the joint between the onset of motion and impact in anteriorposterior (x), vertical (y) and mediallateral (z) directions; fist duration or time from the onset of fist motion to the fist impact; and selective Distance or perpendicular distance from front foot to the target.

To describe kinematics of the technique, spatial and temporal variables at three distinct phases of ready position (or onset of motion), during the punch and finally, at the moment of impact, were extracted.

Fist anterior-posterior displacement of $0.65 \mathrm{~m}$ in approximately $0.3 \mathrm{~s}$ was observed, which indicates a time guide line for participants to execute a powerful punch (table 1). The mean fist maximum velocity of $7.8 \mathrm{~m} / \mathrm{s}$ (table 1) was comparable to results previously published $(6,7,11,12,19)$ 


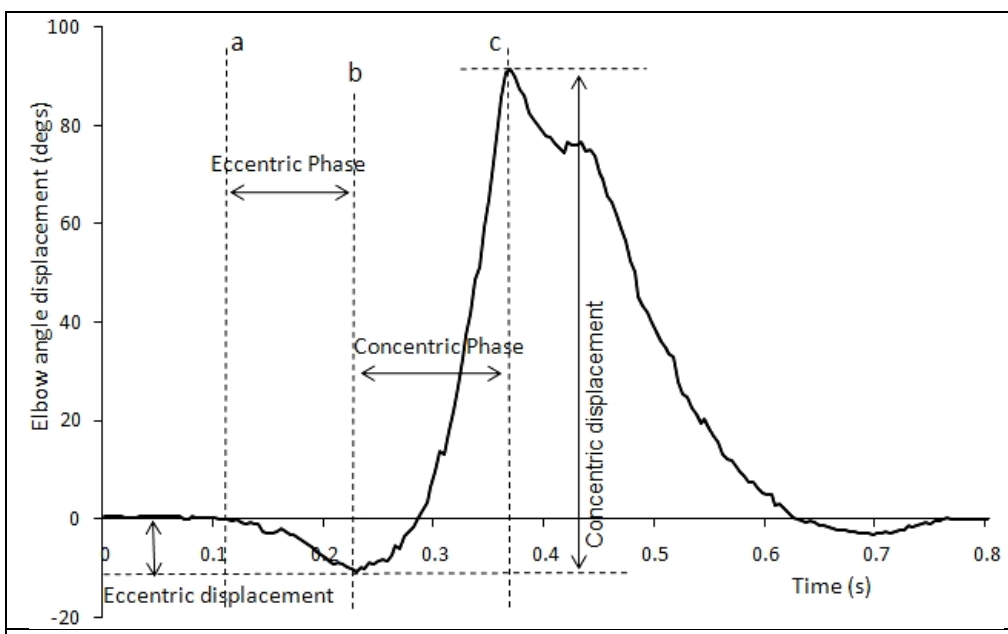

Figure 1. Typical elbow angle displacement time-series graph. Onset of elbow angle (69 degree) has been subtracted from data series. a) The onset of motion or start of flexion (start of eccentric phase); b) end of flexion and start of elbow extension (end of eccentric phase) and c) moment of impact and end of elbow extension (end of concentric phase).

Spatial trajectory of kinematic data series is shown in figure 2. The trajectory provides an important demonstration of changes in various key points such as the intervals between onset of motion and point of impact in two dimensions. Path trajectory of fist in anterior-posterior direction indicates a higher velocity in throwing phase than that portrayed in returning phase. Fist average vertical displacement $(0.125 \mathrm{~m})$, indicates that all subjects irrespective of anthropometrical differences, delivered punches upward rather than downward. Positive value of mean fist $Z$ displacement $(0.056 \mathrm{~m})$ indicates that all participants selected target point medially.

Table 1. Selected linear kinematics from ready position up to the moment of impact.

\begin{tabular}{lcc|}
\hline \multicolumn{1}{|c|}{ Variable } & Mean $\pm \mathrm{SD}$ & min to max \\
\hline FistXDisplacement $(\mathrm{m})$ & $0.655 \pm 0.07$ & 0.516 to 0.766 \\
FistMaxV (m/s) & $7.8 \pm 1.5$ & 6.1 to 9.4 \\
Fist Duration (s) & $0.310 \pm 0.06$ & 0.212 to 0.404 \\
ElbowMaxV (m/s) & $6.7 \pm 1.5$ & 4.3 to 8.5 \\
ShoulderMaxV (m/s) & $3.1 \pm 0.6$ & 2.1 to 3.8 \\
HipXDisplacement (m) & $0.278 \pm 0.06$ & 0.196 to 0.348 \\
HipMaxV (m/s) & $1.6 \pm 0.2$ & 1.1 to 1.8 \\
FistYDisplacement $(\mathrm{m})$ & $0.125 \pm 0.06$ & 0.019 to 0.179 \\
FistZDisplacement $(\mathrm{m})$ & $0.056 \pm 0.05$ & -0.018 to 0.144 \\
SelectiveDistance $(\mathrm{m})$ & $0.496 \pm 0.08$ & 0.387 to 0.648 \\
\hline
\end{tabular}

Max: maximum. V: velocity. X: anterior-posterior direction. Y: vertical direction; Z: mediallateral direction. Selective Distance: perpendicular distance from front foot to target. 
Hip anterior displacement was measured by using the ASIS marker. This forward shift of $28 \mathrm{~cm}$ could represent a weight shift toward intended direction of the punch.

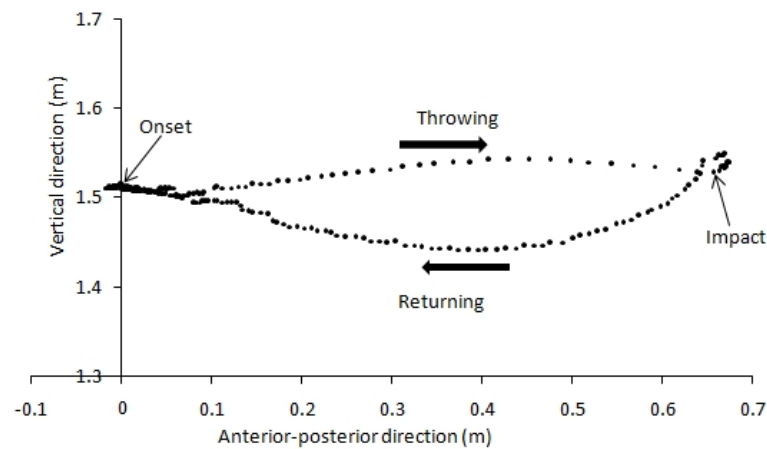

Figure 2. A typical spatial trajectory of fist in sagital plane (raw data). As illustrated above the punch vertical changes in throwing phase is lower than returning phase. Visually considerable greater distance between data points in throwing phase shows more velocity of throwing phase rather than returning phase.

Fist traveled forward, upward and medially by $0.655 \pm 0.07,0.125 \pm 0.06$ and $0.056 \pm 0.05$ $\mathrm{m}$, respectively (table 1). Furthermore, a 3D trajectory of a typical punch was determined using MATLAB version 7 to gain a better insight into the multi-planar movement of the fist motion (figure 3 ).

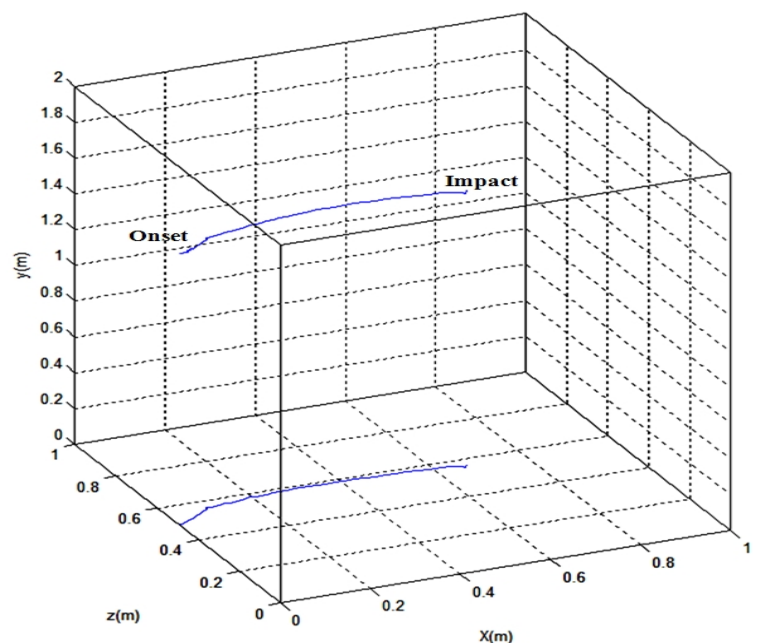

Figure 3. It is a typical three-dimensional trajectory of straight right punch of a boxer. As it can be observed, fist initially (almost one third of distance) travels medially in horizontal plane and simultaneously upward in saggital plane followed by a more straightened trajectory until impact.
Ensemble averaged graphs of joints angle displacements demonstrated mild joint flexion at the start of the punch cycle and followed by a considerable extension, revealing the SSC movement (figure 4). Extension of ankle, knee and elbow begins about 45,60 , and $80 \%$ of the punch cycle, respectively, that would represent the principal of sequential action of muscles.

Effective leg drives and consequently weight shifts in many sporting activities like tennis serves have been found to have several benefits for performance (20-22). Successive extension of ankle and knee of 12 and 25 degree, respectively, implies applying leg drive by boxers (table 4, figure 4).

Selected joints angular kinematics of elbow, shoulder, hip, knee and ankle are shown in tables 2, 3 and 4.
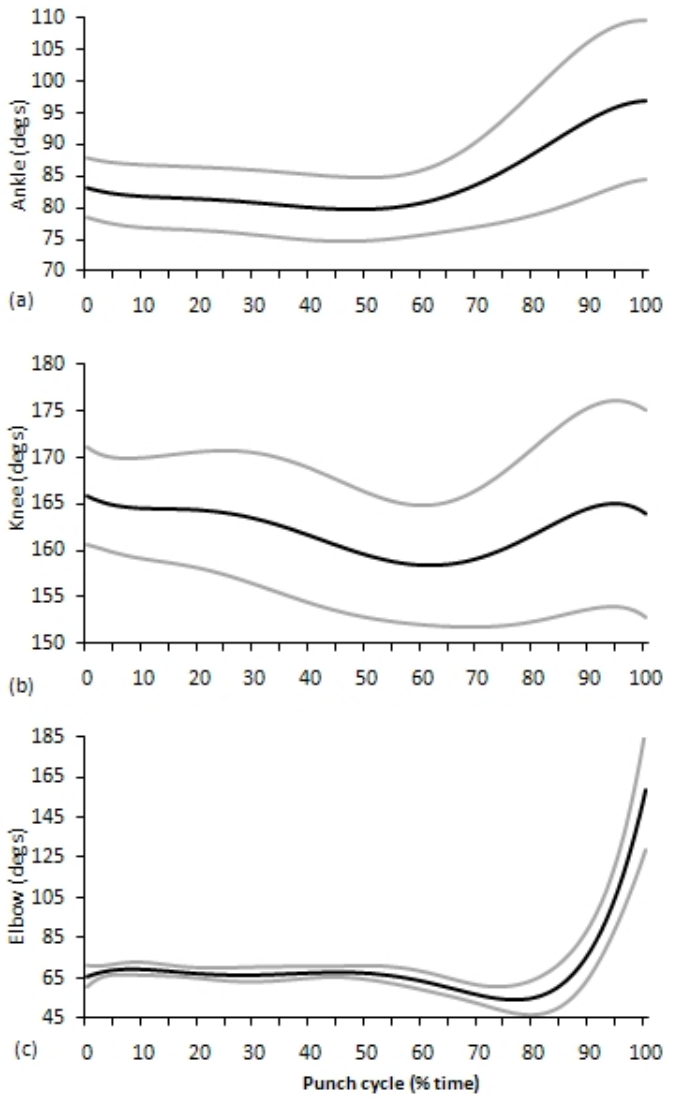

Figure 4. Ensemble averaged time normalized graphs for ankle (a), knee (b) and elbow (c) in punch cycle. Solid black line shows mean angle and gray lines indicate \pm 1 standard deviation from mean. 
Table 2. Selected elbow angular kinematics from ready position up to the

\begin{tabular}{|c|c|c|}
\hline Variable & Mean \pm SD & $\min$ to $\max$ \\
\hline \multicolumn{3}{|l|}{ Elbow } \\
\hline OnsetAngle $\left(^{\circ}\right)$ & $67 \pm 3$ & 63 to 72 \\
\hline MinAngle $\left(^{\circ}\right)$ & $52 \pm 7$ & 42 to 62 \\
\hline ImpactAngle $\left(^{\circ}\right)$ & $137 \pm 12$ & 120 to 155 \\
\hline 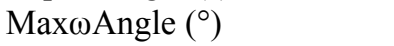 & $112 \pm 16$ & 81 to 134 \\
\hline $\operatorname{Max} \omega(\% / s)$ & $2363 \pm 536$ & 1800 to 3500 \\
\hline 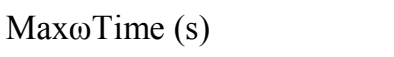 & $0.212 \pm 0.35$ & 0.884 to -0.012 \\
\hline MaxAngle $\left({ }^{\circ}\right)$ & $143 \pm 12$ & 120 to 160 \\
\hline MaxAngleTime (s) & $0.001 \pm 0.01$ & 0.016 to 0.016 \\
\hline EccDuration (s) & $0.123 \pm 0.04$ & 0.056 to 0.172 \\
\hline EccAngleDisplacement $\left({ }^{\circ}\right)$ & $15 \pm 8$ & 3 to 29 \\
\hline ConDuration (s) & $0.105 \pm 0.02$ & 0.076 to 0.136 \\
\hline ConAngleDisplacement $\left(^{\circ}\right)$ & $91 \pm 14$ & 62 to 109 \\
\hline EccTime (s) & $0.228 \pm 0.04$ & 0.292 to -0.156 \\
\hline ConTime (s) & $0.105 \pm 0.02$ & 0.132 to -0.076 \\
\hline
\end{tabular}

Min: minimum. Max: maximum. $\omega$ : angular velocity. Ecc: eccentric phase. Con: concentric phase. Ecc and Con Time: time of eccentric and concentric phase before impact, respectively.

Table3. Selected hip and shoulder angular kinematics from ready position up to the impact.

\begin{tabular}{|c|c|c|}
\hline Variable & Mean \pm SD & $\min$ to $\max$ \\
\hline \multicolumn{3}{|l|}{ Shoulder } \\
\hline OnsetAngle $\left(^{\circ}\right)$ & $20 \pm 4$ & 14 to 28 \\
\hline ImpactAngle $\left({ }^{\circ}\right)$ & $86 \pm 5$ & 81 to 93 \\
\hline MaxAngle $\left(^{\circ}\right)$ & $90 \pm 5$ & 84 to 100 \\
\hline MaxAngleTime (s) & $0.002 \pm 0.01$ & 0.020 to 0.008 \\
\hline \multicolumn{3}{|l|}{ Hip } \\
\hline OnsetAngle $\left(^{\circ}\right)$ & $203 \pm 3$ & 200 to 209 \\
\hline MinAngle $\left({ }^{\circ}\right)$ & $195 \pm 6$ & 188 to 205 \\
\hline ImpactAngle $\left(^{\circ}\right)$ & $196 \pm 7$ & 188 to 208 \\
\hline 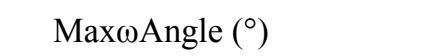 & $209 \pm 4$ & 203 to 217 \\
\hline $\operatorname{Max} \omega(\% / s)$ & $103 \pm 50$ & 50 to 185 \\
\hline MaxwTime (s) & $0.148 \pm 0.04$ & 0.220 to -0.084 \\
\hline MaxAngle $\left(^{\circ}\right)$ & $211 \pm 4$ & 205 to 219 \\
\hline MaxAngleTime (s) & $0.109 \pm 0.03$ & 0.148 to -0.060 \\
\hline EccAngleDisplacement $\left({ }^{\circ}\right)$ & $9 \pm 4$ & 4 to 15 \\
\hline ConDuration (s) & $0.153 \pm 0.12$ & 0.084 to 0.448 \\
\hline ConAngleDisplacement $\left({ }^{\circ}\right)$ & $17 \pm 5$ & 10 to 27 \\
\hline
\end{tabular}

Min: minimum. Max: maximum. $\omega$ : angular velocity. Ecc: eccentric phase. Con: concentric phase. 
Table 4. Selected knee and ankle angular kinematics from ready position to impact.

\begin{tabular}{|c|c|c|}
\hline Variable & Mean \pm SD & $\min$ to $\max$ \\
\hline \multicolumn{3}{|l|}{ Knee } \\
\hline OnsetAngle $\left(^{\circ}\right)$ & $164 \pm 4$ & 158 to 170 \\
\hline MinAngle $\left({ }^{\circ}\right)$ & $155 \pm 7$ & 145 to 168 \\
\hline ImpactAngle $\left(^{\circ}\right)$ & $165 \pm 12$ & 148 to 183 \\
\hline 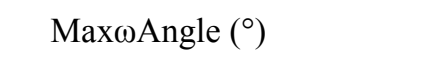 & $162 \pm 7$ & 152 to 172 \\
\hline $\operatorname{Max} \omega(\% / s)$ & $181 \pm 80$ & 109 to 349 \\
\hline Max $\omega$ Time & $0.095 \pm 0.06$ & 0.160 to 0.024 \\
\hline MaxAngle $\left(^{\circ}\right)$ & $167 \pm 9$ & 154 to 177 \\
\hline MaxAngleTime (s) & $0.022 \pm 0.05$ & 0.108 to 0.044 \\
\hline EccDuration (s) & $0.243 \pm 0.08$ & 0.140 to 0.380 \\
\hline EccAngleDisplacement $\left(^{\circ}\right)$ & $9 \pm 6$ & -6 to 18 \\
\hline ConDuration (s) & $0.151 \pm 0.05$ & 0.068 to 0.224 \\
\hline ConAngleDisplacement $\left(^{\circ}\right)$ & $12 \pm 8$ & 5 to 27 \\
\hline EccTime (s) & $0.416 \pm 0.09$ & 0.516 to -0.280 \\
\hline ConTime (s) & $0.173 \pm 0.04$ & 0.216 to -0.104 \\
\hline \multicolumn{3}{|l|}{ Ankle } \\
\hline OnsetAngle $\left(^{\circ}\right)$ & $73 \pm 27$ & 5 to 90 \\
\hline ImpactAngle $\left(^{\circ}\right)$ & $98 \pm 13$ & 78 to 121 \\
\hline $\operatorname{Max} \omega(\% / s)$ & $271 \pm 169$ & 71 to 548 \\
\hline 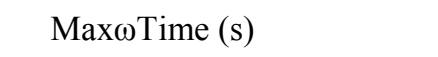 & $0.071 \pm 0.05$ & 0.120 to 0.004 \\
\hline
\end{tabular}

Min: minimum. Max: maximum. $\omega$ : angular velocity. Ecc: eccentric phase. Con: concentric phase. Ecc and Con Time: time of eccentric and concentric phase before impact, respectively.

Table 5 provides the linear velocity of head in three planes. Ensemble averaged graphs of head velocity in medial-lateral and anterior-posterior directions have been depicted in figure 5.

Table 5. Head linear velocity in three directions.

\begin{tabular}{ccc}
\hline Variable & Mean & Min to max \\
\hline $\mathrm{Vx}(\mathrm{m} / \mathrm{s})$ & 1.6 & $1.0-2.0$ \\
$\mathrm{Vy}(\mathrm{m} / \mathrm{s})$ & 0.8 & $0.6-1.0$ \\
$\mathrm{Vz}(\mathrm{m} / \mathrm{s})$ & 1.6 & $1.3-2.1$ \\
\hline
\end{tabular}

$\mathrm{Vx}, \mathrm{Vy}$, and $\mathrm{Vz}$ represent head velocity in anterior-posterior, vertical and medial-lateral direction, respectively.

Head maximum velocity in both anterior and medial directions occurred at $75 \%$ and $85 \%$ of the punch cycle, respectively (figure 5). Head maximal medial velocity happened later than that of anterior velocity in the punch cycle. This was due to the incidence of trunk rotation (not measured) after the leg drive in the kinematic chain. Hence, head medial velocity was concurrent with initiation of elbow extension, so delivering rotational punch like right hook at the moment of opponent's elbow extension would intensify punch impulse. 


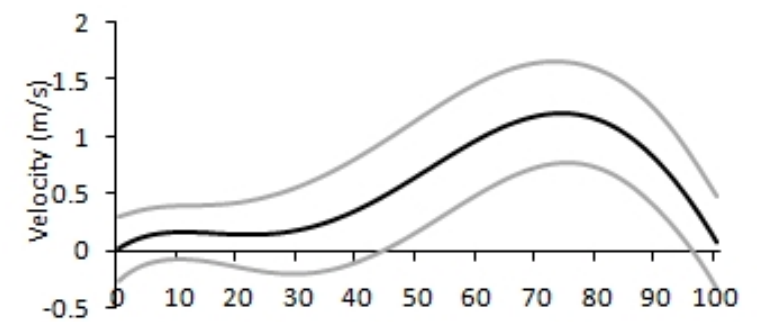

(a)

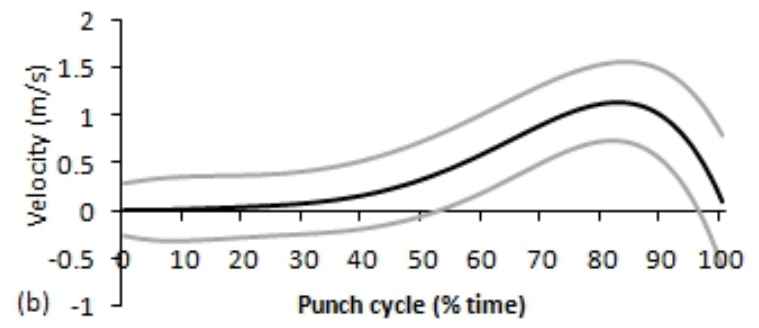

Figure 5. Ensemble averaged time normalized graphs for head velocity. (a) anterior-posterior direction (Vx). (b) medial-lateral direction (Vz). Solid black line shows mean angle and gray lines indicate \pm $1 \mathrm{SD}$ from mean.

\section{DISCUSSION}

Data acquisition indicates that boxers flex joints partially, especially the elbow joint, at the onset of punch cycle which is against their objective to perform the task in minimum time and no additional movements and thus avoiding intent advertisement. Joint partial flexion prior to extension points towards a stretch-shortening cycle (SSC) inherent in boxing performance. Therefore, boxers intuitively have used the universal biomechanical principal of pre-stretch (18) to throw high quality punches as it increases subsequent concentric contraction forces after a short and quick eccentric contraction of agonist muscles (16) and also, help to maximize acceleration path toward intended target.

The apparent difference in punch velocities between throw and return phases is shown in figure 2. The discrepancy should be avoided as it tends to delay preparation for the next attack and would open boxer's guard and consequently provide an opportunity for opponent for gaining point.

Greater values of joint maximum linear velocities encountered in the present study could be an indication that amateur boxers place the emphasis upon speed of the punch as opposed to try and make the punch heavier. Although the intension of the present article is not to compare amateur boxers with professionals, similar findings for professional boxers were reported by Whiting, Gregor, and Finerman (1988) (7). Table 6, provides a basic comparison between the results obtained in this study and that published for professional boxers.

Table 6. A basic comparison of results published by Whiting et al. and that obtained by the present study.

\begin{tabular}{|c|c|c|}
\hline Variable & Whiting et al, 1988 & Present Study \\
\hline Shoulder Max V (m/s) & 2.4 & 3.1 \\
\hline Wrist Max V (m/s) & 6.3 & 7.4 \\
\hline Glove/fist Max V $(\mathrm{m} / \mathrm{s})$ & 6.6 & 7.8 \\
\hline \multicolumn{3}{|l|}{ Elbow } \\
\hline $\operatorname{Max} V(\mathrm{~m} / \mathrm{s})$ & 6.0 & 6.7 \\
\hline Min Angle $\left(^{\circ}\right)$ & $52 \pm 9$ & $52 \pm 7$ \\
\hline Max Angle $\left(^{\circ}\right)$ & $102 \pm 16$ & $143 \pm 12$ \\
\hline $\operatorname{Max} \omega(\% / s)$ & $1261 \pm 320$ & $2363 \pm 536$ \\
\hline Impact Angle $\left(^{\circ}\right)$ & $102 \pm 17$ & $137 \pm 12$ \\
\hline Max $\omega$ Angle $\left(^{\circ}\right)$ & $94 \pm 18$ & $84 \pm 54$ \\
\hline
\end{tabular}

Min: minimum. Max: maximum. V: Velocity. $\omega$ : angular velocity. 
Table 6 points at a considerable difference in elbow angle at the point of impact. While amateur boxers in the current study try to target their opponent from further distances and emphasize high punch velocity, the professional boxers attempt to deliver a heavier punch from closer quarters. To do so, and also to compensate punch impulse because of lower fist velocity, professional heavy weight boxer delivered punch with more elbow flexion to increase punch effective mass (12) by transferring more body momentum.

Here, the main part of the movement took place in sagittal plane, where fist displacement showed that boxers threw knockout punches medially and not exactly straight forward (table 1and figure 3). Partial medial trajectory of fist would thus result in a more efficient transfer of angular momentum produced by trunk rotation.

Execution time of $0.3 \mathrm{~s}$ (table 1) points at the importance of the limited time available for developing this type of explosive movement. Aagaard et al. (2002) (23) have shown that specific strength training can improve the rate of force development (RFD) and that improving RFD results in an enhancement of movement velocities in sports activities. Therefore, to improve the punch velocity, it is necessary to include an explosive strength training program for amateur boxers.

Another issue in kinematic analysis of right punch is the weight transfer or the weight shift. This was shown to occur in numerous studies on golfers to achieve greater club-head velocity and significant differences in the magnitude of the transfer of bodyweight have been observed between golfers of varying ability $(24,25)$. Similar movement was encountered in this study as well and in the shape of a forward motion of the ASIS by $28 \mathrm{~cm}$ in the direction of the target resulting in a general weight shift caused by the Hip motion.
Leg drive is also a biomechanical concept affected by kinematics of motion. In this study, the ankle and knee extensions result in weight transfer from back foot to the front which is the confirmation of the effect of leg drive upon the characteristics of the motion. Furthermore, forward motion of body mass toward target produced by leg drive can be transferred to the smaller body segments in the kinematic chain just prior to impact. This would increase magnitude of punch momentum and velocity as described by two principles of sequential action of muscles (18) and/or segmental interaction principle (26).

Subjects participating in tests were members of different weight classes with different anthropometrics (27).

Brain injury has also been associated with rotational punches like hook (28). Head initial medial-lateral velocity (table 6) could potentially increase the risk of sustaining trauma by the attacker where the combined velocities (attacker fist velocity plus counterattack punch velocity from opponent) could cause severe trauma $(29,30)$. Consequently, head trauma could occur at velocities lower than the range of 7 to $10.5 \mathrm{~m} / \mathrm{s}$ suggested by Unterharnshit (28).

It should also be noted that participants delivered the punch while holding position. Various leg movements such as jumping forward while sparring or during a competition could increase whole body momentum and consequently increase head initial velocity that would intensify the magnitude of the impact when they simultaneously receive counter-attack punch from opponent.

Average elbow maximum angular velocity of $2363 \%$ has been observed in this study. Studies on other sports such as that of baseball players have explained such a high elbow extension velocity. This could also pose a potential risk of elbow injuries (31-33). 


\section{CONCLUSION}

Fundamental to successful boxing performance is optimum punching force (34) that could not be achieved without taking advantage of lower body motion. Leg drive has been observed to build-up momentum in the kinematic chain helping towards greater fist velocity and the effective mass. Therefore, specificity of strength training should focus on lower body kinematics. The obtained data illustrated that all participants followed a similar movement pattern but there were considerable standard deviation in some variables. The concept should be entertained by coaches working on elite boxers. They should not force the athletes to imitate a particular pattern, but should be encouraged to try and enhance individual pattern techniques.

Results of this study suggest that training programs should include plyometrics and explosive strength training to improve both SSC type muscle functions and contractile RFD (35) to improve performance. Distinct elbow angular velocity has been encountered in this study. This should be considered in elbow injury mechanisms. Head velocity reported here could be considered in biomechanical mechanisms of head injuries in boxing. Findings of this descriptive study could be implemented towards performance enhancement and injury but should be regarded cautiously because of the limited sample size.

\section{REFFRENCES}

1. Filimonov VI, Koptsev KN, Husyanov ZM, Nazarov SS. Boxing: Means of increasing strength of the punch. Strength \& Conditioning Journal. 1985;7(6):65-6.

2. Hickey K, Amateur Boxing A. Boxing: The Amateur Boxing Association Coaching Manual: Kaye and Ward; 1980. $304 \mathrm{p}$.

3. Smith MS, Dyson RJ, Hale T, Janaway L. Development of a boxing dynamometer and its punch force discrimination efficacy. Journal of sports sciences. 2000;18(6):445-50.

4. Verkhoshansky YV, Filimonov VI, Husyainov ZM, Garakyan AI. The Dynamics of Punching Technique and Speed-Strength in Young Boxers. Soviet Sports Review. 1991;26(4):160-1.

5. Koryac YA. Assessing Neuromuscular Speed and Speed-Strength in Boxers. Soviet Sports Review. 1991;26(4):195-8.

6. Atha J, Yeadon MR, Sandover J, Parsons KC. The damaging punch. Br Med J (Clin Res Ed). 1985;291(6511):1756-7.

7. Whiting WC, Gregor RJ, Finerman GA. Kinematic analysis of human upper extremity movements in boxing. Am J Sports Med. 1988;16(2):130-6. Epub 1988/03/01.

8. Johnson J, Skorecki J, Wells RP. Peak accelerations of the head experienced in boxing. Medical and biological engineering. 1974;13(3):396-404.

9. Pellman EJ, Viano DC, Tucker AM, Casson IR, Waeckerle JF. Concussion in professional football: reconstruction of game impacts and injuries. Neurosurgery. 2003;53(4):799-812; discussion -4. Epub 2003/10/02.

10. Sherman DC, Bir CA, Walilko TJ, Boitano M, editors. Correlation between punch dynamics and risk of injury. Engineering of Sport 5; 2004; UC Davis, CA.

11. Unterharnscheidt F. Boxing Injuries. In: Fu FH, Stone DA, editors. Sports injuries: mechanisms, prevention, treatment. Baltimore: Williams \& Wilkins; 1994.

12. Walilko TJ, Viano DC, Bir CA. Biomechanics of the head for Olympic boxer punches to the face. British journal of sports medicine. 2005;39(10):710-9.

13. Mullineaux DR, Bartlett RM, Bennett S. Research design and statistics in biomechanics and motor control. Journal of sports sciences. 2001;19(10):739-60. Epub 2001/09/20.

14. Winter DA. Biomechanics and motor control of human movement. 3rd ed: Human kinetic; 2009.

15. Robertson G, Caldwell G, Hamill J, Kamen G, Whittlesey S. Research Methods in Biomechanics. 2nd ed. Champaign: Human Kinetics; 2013.

16. Komi PV, Nicol C. Stretch-Shortening Cycle of Muscle Function. In: Komi PV, editor. Neuromuscular Aspects of Sport Performance: Wiley-Blackwell; 2010. p. 15-31.

17. van Ingen Schenau GJ, Bobbert MF, de Haan A. Original Research TARGET ARTICLE - Does Elastic Energy Enhance Work and Efficiency in the Stretch-Shortening Cycle? Journal of Applied Biomechanics. 1997;13(4):389 - 415.

18. Bartlett R. Sports biomechanics: reducing injury and improving performance. London: E \& FN Spon. Routledge; 2007. 
19. Smith PK, Hamill J. The effects of punching glove type and skill level on momentum transfer. Journal of Human Movement Studies. 1986;12:153-61.

20. Elliott B, Fleisig G, Nicholls R, Escamilia R. Technique effects on upper limb loading in the tennis serve. Journal of science and medicine in sport / Sports Medicine Australia. 2003;6(1):76-87. Epub 2003/06/13.

21. Knudson D. Fundamentals of Biomechanics. 2nd ed: Springer; 2007. 353 p.

22. Miller DI. Body Segment Contributions to Sport Skill Performance: Two Contrasting Approaches. Research Quarterly for Exercise and Sport. 1980;51(1):219-33.

23. Aagaard P, Simonsen EB, Andersen JL, Magnusson P, Dyhre-Poulsen P. Increased rate of force development and neural drive of human skeletal muscle following resistance training. Journal of applied physiology (Bethesda, Md : 1985). 2002;93(4):1318-26. Epub 2002/09/18.

24. Hume PA, Keogh J, Reid D. The role of biomechanics in maximising distance and accuracy of golf shots. Sports medicine (Auckland, NZ). 2005;35(5):429-49. Epub 2005/05/18.

25. Kawashima K, Meshizuka T, Takeshita S, editors. A Kinematic Analysis of Foot Force Exerted on the Soles During the Golf Swing Among Skilled and Unskilled Golfers. Science and Golf III: Proceedings of the World Scientific Congress of Golf; 1998; Champaign, Illinois: Human Kinetics.

26. Knudson D. Qualitative biomechanical principles for application in coaching. Sports biomechanics / International Society of Biomechanics in Sports. 2007;6(1):109-18. Epub 2007/06/05.

27. van den Tillaar R, Ettema G. Effect of body size and gender in overarm throwing performance. European journal of applied physiology. 2004;91(4):413-8. Epub 2003/11/19.

28. Unterharnscheidt F, Higgins L. Pathomorphology of experimental head injury due to rotational acceleration. Acta Neuropathol. 1969;12(2):200-4.

29. Griffiths IW. Principles of Biomechanics \& Motion Analysis: Lippincott Williams \& Wilkins; 2006.339 p.

30. Jordan B. Medical Aspects of Boxing: Taylor \& Francis; 1992. 352 p.

31. Feltner ME, Dapena J. Dynamics of the Shoulder and Elbow Joints of the Throwing Arm During a Baseball Pitch. Journal of Applied Biomechanics. 1986;2(4):235 - 359.

32. Fleisig G. Biomechanics of Baseball Pitching: Implications for Injury and Performance. XXVIII International Symposium of Biomechanics in Sports; Marquette, MI, USA2010. p. 46-50.

33. Werner SL, Murray TA, Hawkins RJ, Gill TJ. Relationship between throwing mechanics and elbow valgus in professional baseball pitchers. Journal of shoulder and elbow surgery / American Shoulder and Elbow Surgeons [et al]. 2002;11(2):151-5. Epub 2002/05/04.

34. Smith M, Draper S. Sport Specific Procedures - Boxing. In: Winter EM, Jones AM, Davison RCR, Bromley PD, Mercer TH, editors. Sport and Exercise Physiology Testing Guidelines: Volume I - Sport Testing: The British Association of Sport and Exercise Sciences Guide. London: Taylor \& Francis: Routledge; 2006.

35. Newton RU, Kraemer WJ. Developing explosive muscular power: Implications for a mixed methods training strategy. Strength \& Conditioning Journal. 1994;16(5):20-31.

Cheraghi, M., et al. (2014). Ann Appl Sport Sci, 2(2): 39-50. 


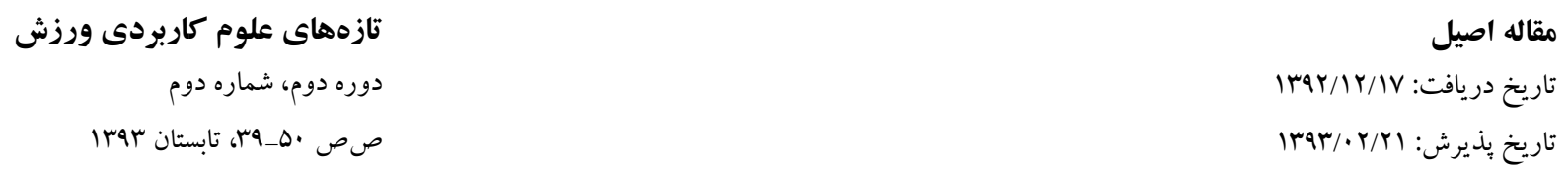

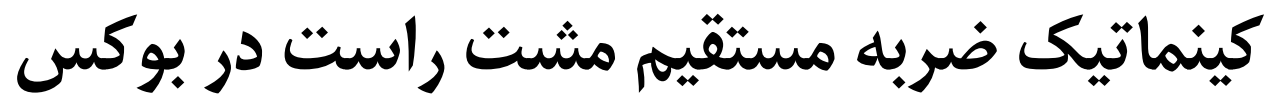

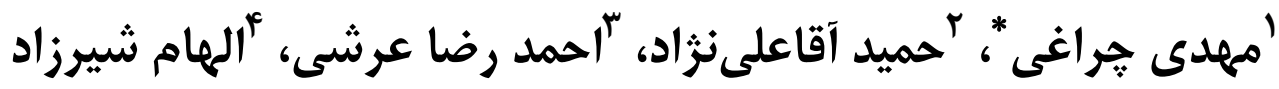

\author{
I. كارشناسى ارشد فيزيولوزى ورزشى، آكادمى ملى المييك و يارالمِيكى جمهورى اسلامى ايران، تهران، ايران.

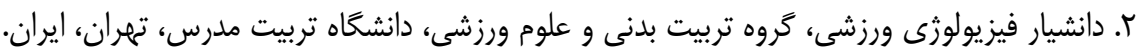

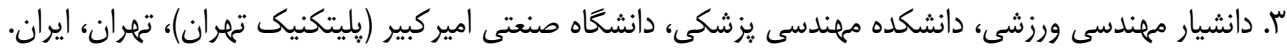

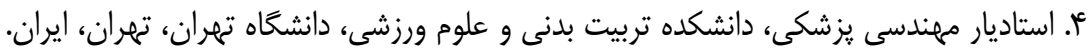

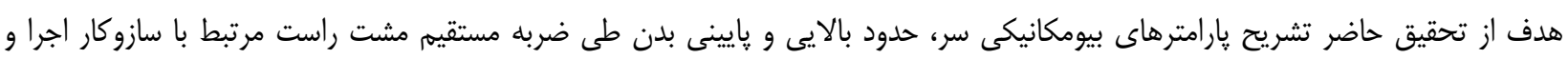

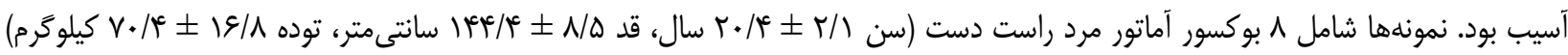

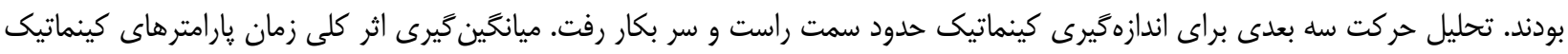

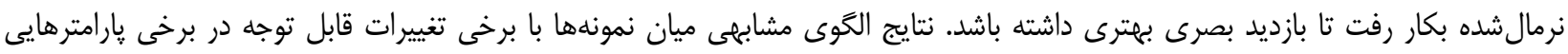

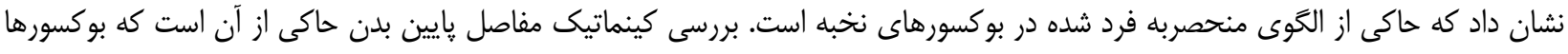

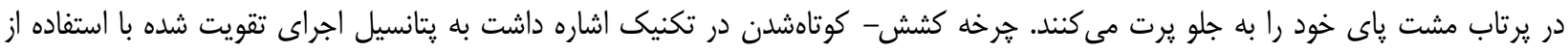

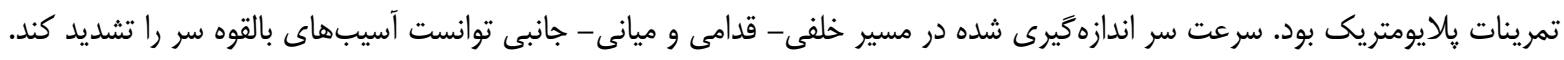

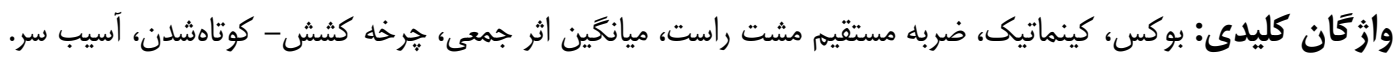

